\title{
Cognitive and Neuropsychiatric Symptom Differences in Early Stages of Alzheimer's Disease: Kuopio ALSOVA Study
}

\author{
Ilona Hallikainen ${ }^{a}$ Anne M. Koivisto ${ }^{a}{ }^{d}$ Teemu Paajanen ${ }^{a}$ \\ Asta Hiltunen ${ }^{f}$ Pertti Karppi $^{g}$ Matti Vanhanen ${ }^{e}$ Tarja Välimäki ${ }^{b, c}$ \\ Sanna-Kaisa Herukka ${ }^{a}$ d Hilkka Soininen ${ }^{a, d}$ Tuomo Hänninen ${ }^{d}$ \\ ${ }^{a}$ Institute of Clinical Medicine, Neurology, ${ }^{b}$ Department of Nursing Science and ${ }^{\mathrm{C} F i n n i s h}$ \\ Doctoral Program in Nursing Science, University of Eastern Finland, dDepartment of Neurology, \\ Kuopio University Hospital, and ${ }^{~}$ Niuvanniemi Hospital, Kuopio, ${ }^{\text {}}$ Department of Neurology, \\ North Karelia Central Hospital, Joensuu, and ${ }^{9}$ Mikkeli Central Hospital, Mikkeli, Finland
}

\section{Key Words}

Alzheimer's disease - Dementia - Memory - Neuropsychiatric symptoms • Neuropsychological tests

\begin{abstract}
Background/Aim: Alzheimer's disease (AD) causes impairment in memory and other cognitive functions as well as neuropsychiatric symptoms and limitations in the activities of daily living (ADL). The aim of this study was to examine whether demographic variables, dementia severity, $A D L$ and neuropsychiatric symptoms are associated with cognition in very mild or mild AD. Methods: We analyzed the baseline data of 236 patients with very mild or mild AD participating in a prospective AD follow-up study (ALSOVA). The Consortium to Establish a Registry for Alzheimer's Disease neuropsychological battery total score was used in the evaluation of the global cognitive performance. Results: Cognition was associated with dementia severity and ADL but not with neuropsychiatric symptoms. ADL functions were associated with both cognitive performance and neuropsychiatric symptoms. Conclusion: Even patients with very mild or mild $A D$ may exhibit neuropsychiatric symptoms not related to cognitive impairment. The results of this study emphasize the importance of taking a multidimensional approach to the diagnostic and prognostic evaluation of AD patients already in the early stages of the disease.
\end{abstract}

Copyright $\odot 2012$ S. Karger AG, Basel 


\section{Introduction}

Alzheimer's disease (AD) is a progressive neurodegenerative disease which is characterized by impairment in cognitive and functional abilities as well as by neuropsychiatric symptoms. Cognitive impairment can include impairment in memory, visuospatial functions, language and executive functions. In addition, neuropsychiatric symptoms, such as depression, apathy and agitation, seem to be common already in early stages of $\mathrm{AD}$ and can have an impact on both patients' and care-givers' well-being [1-3]. Cognitive performance has been consistently associated with functional ability [4-8]; however, the association of neuropsychiatric symptoms with cognition and daily functioning is unclear [7, 9-13], in spite of the fact that the amount of neuropsychiatric symptoms seems to increase in patients with more advanced dementia $[14,15]$. Thus, more information is needed to elucidate how these features of $\mathrm{AD}$ are interrelated.

The Consortium to Establish a Registry for Alzheimer's Disease neuropsychological battery (CERAD-NB) [16] is a widely used, short and reliable measure of cognitive impairment in AD patients $[17,18]$. The method for calculating a total score for the CERAD-NB was published in 2005 [19], and recent studies have supported both the validity and usefulness of the CERAD total score for the detection of mild cognitive impairment and dementia [20-22] as well as for monitoring progression of AD dementia [21]. That is, it seems to be more valuable to use the total score than relying on single subtests. Though the MiniMental State Examination (MMSE) [23] has been commonly used, it has been claimed to be of limited value as a screening instrument $[24,25]$ and in measuring progression of $A D$ [26].

The present study was designed to examine whether global cognitive performance assessed by the CERAD total score is associated with dementia severity, activities of daily living (ADL) and neuropsychiatric symptoms in patients with very mild or mild AD.

\section{Methods}

\section{Subjects}

A total of 241 patients with recently diagnosed very mild or mild AD participated in a prospective AD follow-up study (ALSOVA). The total follow-up period will be up to 5 years $[1,2]$. The aim of the ALSOVA study is to elucidate the effects and cost-efficiency of psychosocial rehabilitation. The study subjects were recruited from April 2002 to September 2006 from the neurology departments of the University Hospital of Kuopio and North-Karelia Central Hospital and from the geriatric memory clinic of the Central Hospital of CentralFinland.

The patients were diagnosed at neurology departments or geriatric memory clinics according to clinical practice, and the diagnosis of AD according to NINCDS-ADRDA guidelines [27] was verified by the research doctor. The baseline data were not used as part of the diagnostic procedure, but it is possible that same methods (e.g. CERAD) have been used. All subjects had very mild or mild dementia at baseline. Finnish speaking, community-dwelling individuals who were free of comorbid conditions that could have affected cognition and who had a loved one as their caregiver were included.

Three subjects from the original study population of 241 subjects were excluded since they were found to have moderate $\mathrm{AD}$, one subject had a diagnosis of Parkinson's disease and another one suffered from blindness. Ultimately, 236 patients fulfilled the inclusion criteria for this part of the study. 


\section{Measures}

The extensive data collected included age, gender, education, physical health, medication, household composition, living arrangements, general well-being, caregiver burden, depression, quality of life and society resource utilization $[1,2]$.

The cognitive evaluation was performed with the CERAD-NB [16] and MMSE [23]. The Finnish version of the CERAD-NB [28] consists of nine subtests; the Delayed Recall of Constructional Praxis and the Clock Drawing Test are additions to the original test battery. The total score for the CERAD-NB was calculated for each participant according to the subtest addition method [19]. The total score was obtained by summing the raw scores from the six subtests (Verbal Fluency Test, modified Boston Naming Test, Word List Memory, Word List Recall, Word List Recognition Discriminability and Constructional Praxis) into a total score (maximum 100 points) according to the original method.

The Clinical Dementia Rating (CDR) scale is a rating scale for evaluating the severity of the memory disorder $[29,30]$. The structured interview protocol includes six areas, and the scores in each of these sections are combined to obtain a composite score and a sum of boxes (SOB) score. The Alzheimer's Disease Cooperative Study - Activities of Daily Living Inventory (ADCS-ADL) is a set of informant-based items describing performance of ADL for patients with AD [4]. The Neuropsychiatric Inventory (NPI) is an informant-based interview that assesses twelve behavioral disturbances occurring in dementia patients [31]. The total NPI score is the sum of the subscale scores (frequency $\times$ severity). Higher scores indicate more behavioral disturbance.

Data were missing for one subject for Constructional Praxis, Delayed Constructional Praxis and Clock Drawing Test because of problems in vision and for another subject for the Word List Recognition because of difficulties understanding the test instructions. Thus, the data for the CERAD total score were missing for two subjects.

\section{Ethical Considerations}

The Ethics Committee of Kuopio University Hospital approved the ALSOVA study protocol. The study participants were recruited from three memory clinics serving three hospital districts. Potential participants received written and oral information of the study, and an initial visit was arranged soon after the diagnosis for those who consented to participate. The voluntary nature of participation and the confidentiality of data collected were emphasized. The informed consent form was signed by both the patients with $\mathrm{AD}$ and their caregivers. The caregivers also provided proxy consent on behalf of the individuals with AD.

\section{Data Analysis}

Descriptive statistics were used to summarize the variables studied and the characteristics of the participants. The data were analyzed with SPSS for Windows 14.0 software package. The $t$ test was used to compare cognition and severity of dementia and the Mann-Whitey U test to compare ADL and neuropsychiatric symptoms between men and women and between CDR 0.5 and 1 groups. Pearson's correlation was used to analyze relations between the CERAD-NB, MMSE, CDR-SOB, age and education. Spearman's correlation was used to analyze the ADCS-ADL or NPI scores. A p value $<0.05$ was considered statistically significant.

\section{Results}

Almost half of the study participants $(\mathrm{n}=115,48.7 \%)$ were men. Most of the patients $(66.1 \%)$ had mild dementia (CDR $=1)$ and $33.9 \%$ had very mild dementia (CDR $=0.5)$. In $70.3 \%$ of cases, the caregiver was a spouse, whereas in $23.7 \%$ of cases, the caregiver was a 
Table 1. Demographic and clinical characteristics of the AD patients participating in the study

\begin{tabular}{|c|c|c|c|c|}
\hline & $\begin{array}{l}\text { CDR } 0.5 \\
(n=80)\end{array}$ & $\begin{array}{l}\text { CDR } 1 \\
(n=156)\end{array}$ & $\begin{array}{l}\text { All } \\
(n=236)\end{array}$ & $p$ value* \\
\hline Female, \% & 53.8 & 50 & 51.3 & \\
\hline Age, years & $\begin{array}{l}73.85 \pm 6.95 \\
(56-87)\end{array}$ & $\begin{array}{l}75.75 \pm 6.26 \\
(53-90)\end{array}$ & $\begin{array}{l}75.11 \pm 6.55 \\
(53-90)\end{array}$ & 0.245 \\
\hline Education, years & $\begin{array}{l}8.14 \pm 3.32 \\
(1-18)\end{array}$ & $\begin{array}{l}7.25 \pm 3.25 \\
(1-20)\end{array}$ & $\begin{array}{l}7.55 \pm 3.29 \\
(1-20)\end{array}$ & 0.350 \\
\hline CERAD total score ${ }^{1}$ (scale $0-100$ ) & $\begin{array}{l}56.09 \pm 12.63 \\
(25-96)\end{array}$ & $\begin{array}{l}49.28 \pm 10.77 \\
(22-82)\end{array}$ & $\begin{array}{l}51.58 \pm 11.85 \\
(22-96)\end{array}$ & $<0.001$ \\
\hline MMSE score (scale 0-30) & $\begin{array}{l}23.22 \pm 2.95 \\
(16-30)\end{array}$ & $\begin{array}{l}20.62 \pm 3.34 \\
(12-30)\end{array}$ & $\begin{array}{l}21.5 \pm 3.44 \\
(12-30)\end{array}$ & $<0.001$ \\
\hline CDR-SOB score (scale 0-18) & $\begin{array}{l}2.60 \pm 0.70 \\
(1-3.5)\end{array}$ & $\begin{array}{l}4.91 \pm 1.13 \\
(3-8)\end{array}$ & $\begin{array}{l}4.13 \pm 1.49 \\
(1-8)\end{array}$ & $<0.001$ \\
\hline ADCS-ADL score (scale $0-78$ ) & $\begin{array}{l}69.63 \pm 5.99 \\
(50-78)\end{array}$ & $\begin{array}{l}61.91 \pm 8.78 \\
(34-76)\end{array}$ & $\begin{array}{l}64.53 \pm 8.73 \\
(34-78)\end{array}$ & $<0.001$ \\
\hline NPI score $(0-144)$ & $\begin{array}{l}6.31 \pm 7.25 \\
(0-32)\end{array}$ & $\begin{array}{l}10.16 \pm 10.63 \\
(0-49)\end{array}$ & $\begin{array}{l}8.86 \pm 9.78 \\
(0-49)\end{array}$ & 0.028 \\
\hline
\end{tabular}

Values are mean \pm SD with ranges in parentheses, unless indicated otherwise.

* Pairwise comparisons of the difference between very mild $(\mathrm{CDR}=0.5)$ and mild $(\mathrm{CDR}=1) \mathrm{AD}$ dementia, significance of difference in two-tailed t test or Mann-Whitney $U$ test, calculated by Bonferroni correction. ${ }^{1} \mathrm{n}=234$.

child. The remaining $6 \%$ of caregivers were siblings or children's spouses. On average, the participants were recruited 5 months after diagnosis. Almost all patients (96.2\%) were on AD medication, with $93.8 \%$ of them using acetylcholine esterase inhibitors and $6.2 \%$ using memantine. Table 1 shows the mean age, education in years, CDR-SOB score, CERAD total score, MMSE score, ADCS-ADL score and NPI total score. Only 18.2\% of the participants had no neuropsychiatric symptoms, $21.6 \%$ had one symptom, $13.1 \%$ two and $47.0 \%$ displayed symptoms in at least three different NPI domains. The most common neuropsychiatric symptoms were apathy (48.3\%), depression (36.4\%) and irritability (33.9\%).

There was no significant difference in the CERAD total score, MMSE score, CDR-SOB score or NPI score between men and women. Women performed better on the ADCS-ADL than men $(\mathrm{z}=-4.287, \mathrm{p}<0.001)$. Not surprisingly, participants with very mild dementia $(\mathrm{CDR}=0.5)$ outperformed those with mild dementia $(\mathrm{CDR}=1)$ on the CERAD total score $(\mathrm{t}(2,232)=4.308, \mathrm{p}<0.001)$ and MMSE score $(\mathrm{t}(2,234)=5.886, \mathrm{p}<0.001)$, received a lower NPI total score $(\mathrm{z}=-2.892, \mathrm{p}=0.028)$ and a greater ADCS-ADL score $(\mathrm{z}=-7.032, \mathrm{p}<0.001$; table 1). Table 2 shows the results of the correlation analyses between age and education and CERAD total, MMSE, CDR-SOB and ADCS-ADL scores. The length of education was positively correlated with the CERAD total score and the MMSE score, but there was no significant correlation between age and the CERAD total score or age and the MMSE score. Age correlated negatively with ADCS-ADL scores, and education correlated negatively with CDR-SOB scores and positively with ADCS-ADL scores. NPI scores did not correlate with education or age.

Table 2 shows the results of the correlation analyses between the CERAD total, MMSE, CDR-SOB, ADCS-ADL and NPI total scores. The CDR-SOB score was negatively correlated with the CERAD total and MMSE scores, whereas the ADCS-ADL score was positively correlated with the CERAD total and MMSE scores. We also analyzed the correlation between 
Table 2. Correlations between demographic and clinical characteristics of the AD patients participating in the study

\begin{tabular}{|c|c|c|c|c|c|}
\hline & $\begin{array}{l}\text { CERAD } \\
\text { total score }\end{array}$ & $\begin{array}{l}\text { MMSE } \\
\text { score }^{\dagger}\end{array}$ & $\begin{array}{l}\text { CDR-SOB } \\
\text { score }^{\dagger}\end{array}$ & $\begin{array}{l}\text { ADCS-ADL } \\
\text { score }^{\ddagger}\end{array}$ & $\begin{array}{l}\text { NPI } \\
\text { score }^{\ddagger}\end{array}$ \\
\hline Education (years) & $0.334^{* * *}$ & $0.278^{* * *}$ & $-0.204^{*}$ & $0.357^{* * *}$ & -0.092 \\
\hline Age (years) & 0.062 & 0.035 & 0.159 & $-0.201^{*}$ & -0.073 \\
\hline CERAD total score & & $0.618^{* * *}$ & $-0.319^{* * *}$ & $0.250^{* * *}$ & -0.087 \\
\hline MMSE score & & & $-0.443^{* * *}$ & $0.314^{* * *}$ & 0.049 \\
\hline CDR-SOB score & & & & $-0.580^{* * *}$ & $0.231^{* * *}$ \\
\hline ADCS-ADL score & & & & & $-0.339 * * *$ \\
\hline
\end{tabular}

${ }^{* * *} \mathrm{p}<0.001,{ }^{*} \mathrm{p}<0.05$, calculated by Bonferroni correction. ${ }^{\dagger}$ Pearson's product-moment correlation coefficient; ${ }^{\ddagger}$ Spearman's rank correlation coefficient.

the CERAD total and ADCS-ADL scores separately for subjects with low education $(\leq 8$ years) and subjects with high education ( $\geq 9$ years). The correlation was stronger in the more educated group $(\mathrm{r}=0.351, \mathrm{p}=0.009)$ but was significant also in the low-educated group $(\mathrm{r}=$ $0.186, \mathrm{p}=0.013$ ). The ADCS-ADL score was negatively correlated with the CDR-SOB score. The NPI total score was not correlated with the CERAD total score or the MMSE score. We also analyzed the correlation between the CERAD total and NPI scores separately in lowand high-educated groups and got similar results. None of the NPI subscales was correlated with the CERAD total score and none of the CERAD subtests was correlated with the NPI total score. The NPI total score was positively correlated with CDR-SOB score and negatively with ADCS-ADL scores.

\section{Discussion}

In this study, we investigated correlations between the CERAD total score, ADL and neuropsychiatric measures in a large group of systematically documented AD patients with very mild or mild dementia. Almost all of them used medication for AD. They all participated in a longitudinal study focusing on the effects and cost-efficiency of early psychosocial rehabilitation. There have been very few studies using the CERAD total score to measure cognitive performance in $\mathrm{AD}$ patients. In our study, CERAD total score correlated with the MMSE. As expected, participants with clinical staging of very mild dementia $(C D R=0.5)$ outperformed those with mild dementia $(\mathrm{CDR}=1)$. These findings are consistent with results from previous studies $[19,21,22]$.

The influence of education on the results of the CERAD-NB subtests has been noted in many studies, but the influence of age and gender has varied across studies [17, 19, 32-35]. Consistent with data on the CERAD subtests for a sample of elderly Finns [33], our results in the AD sample revealed a correlation between the CERAD total score and education but not between the CERAD total score and age. There was no difference in the CERAD total score between genders. Our results are in agreement with those of previous studies about the importance of taking into account the educational level of $\mathrm{AD}$ patients in any evaluation of cognitive performance conducted with the CERAD-NB.

Although the mean NPI total score is relatively low, it can represent for example several occasional mild symptoms or two weekly moderate symptoms or one severe symptom. The 
mean NPI score in our AD sample is consistent with previous studies with comparable groups of patients [36]. We have previously reported that these symptoms have an impact on both patients' and care-givers' well-being already in early stages of AD $[1,2]$. Studies in patients with mild cognitive impairment show that neuropsychiatric symptoms may be a predictor of conversion to $\mathrm{AD}$ [37], which emphasizes the role of evaluation of these symptoms already in the early phase of the disease.

There are very few studies where the CERAD total score was used as a measure of cognitive function in the evaluation of associations between cognitive performance, functional ability and neuropsychiatric symptoms. In our study, cognition was significantly associated with ADL. These results are consistent with those from previous studies conducted with the CERAD total score [22] or other cognitive measures [4, 5, 7-9]. Women received better scores in the ADCS-ADL, which probably reflects the traditional way to share housework in marriages in this generation, and this needs to be taken into account when using ADL measures. An association was also detected between ADL and neuropsychiatric symptoms. There are many previous findings indicating that neuropsychiatric symptoms are associated with functional limitations $[6,7,11,13]$, although some studies have found contrasting results $[5,9]$.

Most reports in the literature indicate that behavioral symptoms and cognition are not related $[10,11]$ or that the relationship is weak $[7,12]$. There is also evidence that any change in behavioral symptoms is independent from changes occurring in cognitive measures [9]. Instead, Harwood et al. [6] described a relationship between psychological and behavioral disturbances and MMSE scores. Our study, using the CERAD total score and MMSE score, indicates that neuropsychiatric symptoms were not correlated with cognitive performance. Our results are consistent with most of the previous evidence, showing that cognitive and behavioral disturbances are rather distinct entities in $\mathrm{AD}$, at least in the mild stage of the disease. Although the correlations between other clinical characteristics (CERAD total, ADCS-ADL, NPI and CDR-SOB scores) were fairly modest (0.23-0.58), they were clearly significant and, on the contrary, the correlations between cognition and neuropsychiatric symptoms did not imply even a tendency of association.

There are some limitations to this study. All patients and their caregivers voluntarily participated in this 5-year follow-up study and met regularly with the study nurse and psychologist. Some of the subjects were randomly selected to participate in early psychosocial intervention. Therefore, this voluntary participation procedure may have produced a selection bias. Thus, this study population may not completely represent the general population of patients with very mild or mild AD. Andersen et al. [38] have reported that recruitment from clinical practice and population-based screening represent study samples with different demographic characteristics.

Our study population at baseline was homogenous in terms of recently diagnosed very mild or mild AD. Therefore, results cannot be generalized to patients with more advanced dementia. The educational level of older persons in Finland is often lower than in other Western countries, and this needs to be considered when interpreting results. Despite these limitations, our results strongly support previous studies.

The strength of our study was the use of several different measures and a more extensive cognitive evaluation than the MMSE in a fairly large study population. Subsequently, it would be valuable to monitor how cognition, neuropsychiatric symptoms and ADL change with time, and to obtain more information about the usability of the CERAD total score in follow-up studies. This kind of follow-up data could also help to find factors that would predict the progression rate of AD.

In conclusion, we detected that cognitive performance was not associated with neuropsychiatric symptoms, but that ADL were associated with both of these factors. It is evident 
that both the cognitive level and neuropsychiatric symptoms affect the patients' ability to cope with the demands in everyday life. Our results help to provide information to patients and their caregivers about symptoms during the first years of the disease. Our findings emphasize the need for a multifaceted evaluation of AD symptoms in both the clinical and research setting.

\section{Appendix: ALSOVA Study Group}

Hilkka Soininen, MD, Professor, project director: Department of Neurology, Kuopio University Hospital and School of Medicine, Institute of Clinical Medicine, Neurology, University of Eastern Finland, Kuopio Campus, Finland.

Anne Koivisto, $\mathrm{PhD}, \mathrm{MD}$, specialist in neurology, study coordinator and principal investigator: Department of Neurology, Kuopio University Hospital and School of Medicine, Institute of Clinical Medicine, Neurology, University of Eastern Finland, Kuopio Campus, Finland.

Ilona Hallikainen, MPsych, psychologist: Brain Research Unit, Clinical Research Centre, University of Eastern Finland, Kuopio Campus, Finland.

Sanna-Kaisa Herukka, PhD, researcher: Department of Neurology, Kuopio University Hospital and School of Medicine, Institute of Clinical Medicine, Neurology, University of Eastern Finland, Kuopio Campus, Finland.

Asta Hiltunen, MD, specialist in neurology: Department of Neurology, North Karelia Central Hospital, Finland.

Janne Martikainen, PhD, research director: School of Pharmacy, University of Eastern Finland, Kuopio Campus, Finland.

Helena Mäkelä, study nurse: Brain Research Unit, Clinical Research Centre, University of Eastern Finland, Kuopio Campus, Finland.

Pertti Karppi, MD, geriatrician: Mikkeli Central Hospital, Finland.

Kristiina Hongisto, MD, geriatrician: Institute of Public Health and Clinical Nutrition, Department of Geriatrics, University of Eastern Finland, Kuopio Campus, Finland and School of Medicine, Institute of Clinical Medicine, Neurology, University of Eastern Finland, Kuopio Campus, Finland.

Teemu Paajanen, MPsych, psychologist: Brain Research Unit, Clinical Research Centre, University of Eastern Finland, Kuopio Campus, Finland.

Anna-Maija Pietilä, PhD, Professor: Department of Nursing Science, University of Eastern Finland, Kuopio Campus, Finland.

Juhani Sivenius, MD, Professor: Brain Research and Rehabilitation Center Neuron, Department of Neurology, Kuopio University Hospital and School of Medicine, Institute of Clinical Medicine, Neurology, University of Eastern Finland, Kuopio Campus, Finland.

Hannu Valtonen, PhD, Professor: Department of Health and Social Management, University of Eastern Finland, Kuopio Campus, Finland.

Matti Vanhanen, PhD, neuropsychologist: Niuvanniemi Hospital, Kuopio, Finland.

Katri Vehviläinen-Julkunen, Professor: Department of Nursing Science, University of Eastern Finland, Kuopio Campus, Finland.

Tarja Välimäki, MNSc: Department of Nursing Science, University of Eastern Finland, Kuopio Campus, Finland. 


\section{Acknowledgements}

This study was supported by grants from the Yrjö-Jahnsson Foundation, Hospital Neuron, Kuopio University Hospital (EVO-grant 5220/5772728) and the Social Insurance Institute of Finland (Kela). The authors gratefully acknowledge the contribution of the late Professor Tuula Pirttilä, project director 2002-2009. The authors also thank study nurse Helena Mäkelä for her invaluable help in organizing and performing the examinations of the study subjects, Vesa Kiviniemi, PhD, for checking statistics and the patients and their caregivers for their time and effort.

\section{Disclosure Statement}

The authors have no conflicts to disclose. The sponsors had neither a role in the analysis or interpretation of these data, nor in the content of the article.

\section{References}

-1 Välimäki TH, Vehviläinen-Julkunen KM, Pietilä AM, Pirttilä TA: Caregiver depression is associated with a low sense of coherence and health-related quality of life. Aging Ment Health 2009;13:799-807.

-2 Karttunen K, Karppi P, Hiltunen A, Vanhanen M, Välimäki T, Martikainen J, Valtonen H, Sivenius J, Soininen H, Hartikainen S, Suhonen J, Pirttilä T; ALSOVA study group: Neuropsychiatric symptoms and quality of life in patients with very mild and mild Alzheimer's disease. Int J Geriatr Psychiatry 2011;26:473-82.

-3 Rocca P, Leotta D, Liffredo C, Mingrone C, Sigaudo M, Capellero B, Rocca G, Simoncini M, Pirfo E, Bogetto F: Neuropsychiatric symptoms underlying caregiver stress and insight in Alzheimer's disease. Dement Geriatr Cogn Disord 2010;30:57-63.

-4 Galasko D, Bennett D, Sano M, Ernesto C, Thomas R, Grundman M, Ferris S: An inventory to assess activities of daily living for clinical trials in Alzheimer's disease. The Alzheimer's Disease Cooperative Study. Alzheimer Dis Assoc Disord 1997;11(suppl 2):S33-S39.

-5 Green CR, Marin DB, Mohs RC, Schmeidler J, Aryan M, Fine E, Davis KL: The impact of behavioral impairment of functional ability in Alzheimer's disease. Int J Geriatr Psychiatry 1999;14:307-316.

-6 Harwood DG, Barker WW, Ownby RL, Duara R: Relationship of behavioral and psychological symptoms to cognitive impairment and functional status in Alzheimer's disease. Int J Geriatr Psychiatry 2000;15:393-400.

-7 Tekin S, Fairbanks LA, O'Connor S, Rosenberg S, Cummings JL: Activities of daily living in Alzheimer's disease: neuropsychiatric, cognitive, and medical illness influences. Am J Geriatr Psychiatry 2001;9:81-86.

8 Bouwens SF, van Heugten CM, Verhey FR: Association between cognition and daily life functioning in dementia subtypes. Int J Geriatr Psychiatry 2009;24:764-769.

-9 Tractenberg RE, Weiner MF, Cummings JL, Patterson MB, Thal LJ: Independence of changes in behavior from cognition and function in community-dwelling persons with Alzheimer's disease: a factor analytic approach. J Neuropsychiatry Clin Neurosci 2005;17:51-60.

$\checkmark 10$ Lam LC, Leung T, Lui VW, Leung VP, Chiu HF: Association between cognitive function, behavioral syndromes and two-year clinical outcome in Chinese subjects with late-onset Alzheimer's disease. Int Psychogeriatr 2006;18:517-526.

-11 Peters KR, Rockwood K, Black SE, Bouchard R, Gauthier S, Hogan D, Kertesz A, Loy-English I, Beattie BL, Sadovnick AD, Feldman HH: Characterizing neuropsychiatric symptoms in subjects referred to dementia clinics. Neurology 2006;66:523-528.

-12 Starr JM, Lonie J: Relationship between behavioural and psychological symptoms of dementia and cognition in Alzheimer's disease. Dement Geriatr Cogn Disord 2007;24:343-347. 
-13 Okura T, Plassman BL, Steffens DC, Llewellyn DJ, Potter GG, Langa KM: Prevalence of neuropsychiatric symptoms and their association with functional limitations in older adults in the United States: the aging, demographics, and memory study. J Am Geriatr Soc 2010;58:330-337.

$\checkmark 14$ Steinberg M, Shao H, Zandi P, Lyketsos CG, Welsh-Bohmer KA, Norton MC, Breitner JC, Steffens DC, Tschanz JT; Cache County Investigators: Point and 5-year period prevalence of neuropsychiatric symptoms in dementia: the Cache County Study. Int J Geriatr Psychiatry 2008;23:170-177.

-15 Yener GG; Turkuaz Alzheimer Working (TAC) Group: The neuropsychiatric inventory scores changes across the Mini Mental State Examination ranges in patients with Alzheimer's disease: a multicenter study in Turkey. Cogn Behav Neurol 2009;22:264-269.

-16 Morris JC, Heyman A, Mohs RC, Hughes JP, van Belle G, Fillenbaum G, Mellits ED, Clark C: The Consortium to Establish a Registry for Alzheimer's Disease (CERAD). Part I. Clinical and neuropsychological assessment of Alzheimer's disease. Neurology 1989;39:1159-1165.

$\checkmark 17$ Welsh KA, Butters N, Mohs RC, Beekly D, Edland S, Fillenbaum G, Heyman A: The Consortium to Establish a Registry for Alzheimer's Disease (CERAD). Part V. A normative study of the neuropsychological battery. Neurology 1994;44:609-614.

18 Hänninen T, Pulliainen V, Salo J, Hokkanen L, Erkinjuntti T, Koivisto K, Viramo P, Soininen H: Cognitive tests in diagnosing memory disorders and early dementia: CERAD-neuropsychological battery (in Finnish). Suom Lääkäril 1999;54:1967-1975.

-19 Chandler MJ, Lacritz LH, Hynan LS, Barnard HD, Allen G, Deschner M, Weiner MF, Cullum CM: A total score for the CERAD neuropsychological battery. Neurology 2005;65:102-106.

-20 Paajanen T, Hänninen T, Tunnard C, Mecocci P, Sobow T, Tsolaki M, Vellas B, Lovestone S, Soininen $\mathrm{H}$; Addneuromed Consortium: CERAD neuropsychological battery total score in multinational mild cognitive impairment and control populations: the AddNeuroMed study. J Alzheimers Dis 2010;22:1089-1097.

-21 Rossetti HC, Munro Cullum C, Hynan LS, Lacritz LH: The CERAD Neuropsychologic Battery Total Score and the progression of Alzheimer disease. Alzheimer Dis Assoc Disord 2010;24:138-142.

-22 Seo EH, Lee DY, Lee JH, Choo IH, Kim JW, Kim SG, Park SY, Shin JH, Do YJ, Yoon JC, Jhoo JH, Kim KW, Woo JI: Total scores of the CERAD neuropsychological assessment battery: validation for mild cognitive impairment and dementia patients with diverse etiologies. Am J Geriatr Psychiatry 2010; 18:801-809.

-23 Folstein MF, Folstein SE, McHugh PR: 'Mini-mental state'. A practical method for grading the cognitive state of patients for the clinician. J Psychiatr Res 1975;12:189-198.

24 Ashford JW: Screening for memory disorders, dementia and Alzheimer's disease. Aging Health 2008; 4:399-432.

25 Mitchell AJ: A meta-analysis of the accuracy of the mini-mental state examination in the detection of dementia and mild cognitive impairment. J Psychiatr Res 2009;43:411-431.

-26 Clark CM, Sheppard L, Fillenbaum GG, Galasko D, Morris JC, Koss E, Mohs R, Heyman A: Variability in annual Mini-Mental State Examination score in patients with probable Alzheimer disease: a clinical perspective of data from the Consortium to Establish a Registry for Alzheimer's Disease. Arch Neurol 1999;56:857-862.

27 McKhann G, Drachman D, Folstein M, Katzman R, Price D, Stadlan EM: Clinical diagnosis of Alzheimer's disease: report of the NINCDS-ADRDA Work Group under the auspices of Department of Health and Human Services Task Force on Alzheimer's Disease. Neurology 1984;34:939-944.

28 Pulliainen V, Hokkanen L, Salo J, Hänninen T: CERAD-kognitiivinen tehtäväsarja. Käsikirja. [Manual of the Finnish version of the CERAD neuropsychological battery]. Kuopio, Suomen Alzheimertutkimusseura ry, 1999.

-29 Morris JC: The Clinical Dementia Rating (CDR): current version and scoring rules. Neurology 1993; 43:2412-2414.

-30 Hughes CP, Berg L, Danziger WL, Coben LA, Martin RL: A new clinical scale for the staging of dementia. Br J Psychiatry 1982;140:566-572.

-31 Cummings JL, Mega M, Gray K, Rosenberg-Thompson S, Carusi DA, Gornbein J: The Neuropsychiatric Inventory: comprehensive assessment of psychopathology in dementia. Neurology 1994;44: 2308-2314.

-32 Ganguli M, Ratcliff G, Huff FJ, Belle S, Kancel MJ, Fischer L, Seaberg EC, Kuller LH: Effects of age, gender, and education on cognitive tests in a rural elderly community sample: norms from the Monongahela Valley Independent Elders Survey. Neuroepidemiology 1991;10:42-52. 
33 Karrasch M, Laine M: Age, education and test performance on the Finnish CERAD. Acta Neurol Scand 2003;108:97-101.

-34 Beeri MS, Schmeidler J, Sano M, Wang J, Lally R, Grossman H, Silverman JM: Age, gender, and education norms on the CERAD neuropsychological battery in the oldest old. Neurology 2006;67:10061010 .

- 35 Sosa AL, Albanese E, Prince M, Acosta D, Ferri CP, Guerra M, Huang Y, Jacob KS, de Rodriguez JL, Salas A, Yang F, Gaona C, Joteeshwaran A, Rodriguez G, de la Torre GR, Williams JD, Stewart R: Population normative data for the 10/66 Dementia Research Group cognitive test battery from Latin America, India and China: a cross-sectional survey. BMC Neurol 2009;9:48.

- 36 Kavanagh S, Gaudig M, Van Baelen B, Adami M, Delgado A, Guzman C, Jedenius E, Schauble B: Galantamine and behavior in Alzheimer's disease: analysis of four trials. Acta Neurol Scand 2011; 124:302-308.

- 37 Teng E, Lu PH, Cummings JL: Neuropsychiatric symptoms are associated with progression from mild cognitive impairment to Alzheimer's disease. Dement Geriatr Cogn Disord 2007;24:253-259.

38 Andersen F, Engstad TA, Straume B, Viitanen M, Halvorsen DS, Hykkerud S, Sjøbrend K: Recruitment methods in Alzheimer's disease research: general practice versus population based screening by mail. BMC Med Res Methodol 2010;10:35. 